\title{
Customizing photoredox properties of PXX-based dyes through energy level rigid shifts of frontier molecular orbitals.
}

Andrea Sciutto, Andrea Fermi, Andrea Folli, Tommaso Battisti, Joseph M. Beames, Damien M. Murphy and Davide Bonifazi*

[*] A. Sciutto, Dr. A. Fermi, Dr. A. Folli, T. Battisti, Dr. J. M. Beames, Prof. Dr. D. M. Murphy and Prof. Dr. D. Bonifazi School of Chemistry, Cardiff University, Park Place, Cardiff CF10 3AT, United Kingdom. E-mail: bonifazidecardiff.ac.uk

Abstract: Here we describe the synthesis of electron-rich PXX derivatives in which the energy levels of the excited states have been rigidly shifted through the insertion of imide groups. This has allowed the development of a new series of oxygen-doped photoredox-active chromophores with improved oxidizing and reducing properties. Capitalizing on the dehalogenation of organic halides as a model reaction, we could investigate the photooxidative and photoreductive potential of these molecules in model chemical transformations. Depending on the substrate, solvent and dye the reaction mechanism can follow different paths. This prompted us to consider the first chemoselective transformation protocol, in which two different C-Br bonds could be chemoselectively reacted through the sequential photoactivation of two different colorants.

\section{Fig. for the Table of Contents}

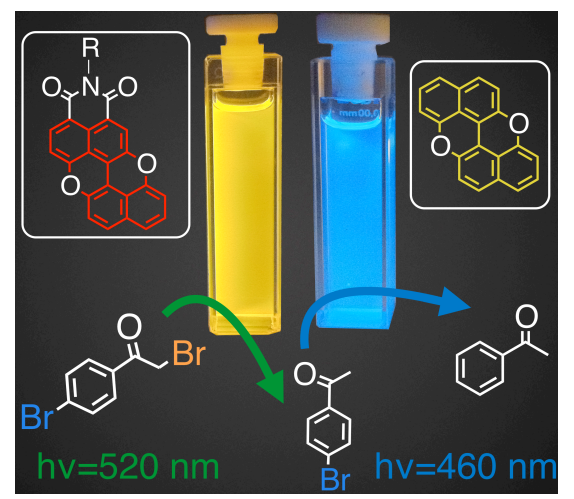




\section{Introduction}

Chromophores ${ }^{[1]}$ are attracting great interest in organic chemistry for their open-shell configuration of excited states which are able to emit light or trigger chemical transformations. ${ }^{[2-4]}$ In particular, organic chromophores are emerging as metal-free alternatives to highly exploited, yet expensive, Ru(II)- and Ir(III)-complexes. ${ }^{[5-10]}$ Until now, efforts in the field have rarely focused on the rational design of dyes featuring excited states with tailored photoredox properties. ${ }^{[11,12]}$ In fact, understanding the behavior of chromophores depicting programmed redox potentials in photo-triggered chemical transformations is crucial to unravel those mechanistic insights that otherwise would be difficult because of their intrinsic irreversibility.[13,14] Furthermore, gaining control on the redox potentials of excited states could enable the development of chemoselective reactions triggered by specific excitation wavelengths, as recently proposed by König et al. ${ }^{[15]}$
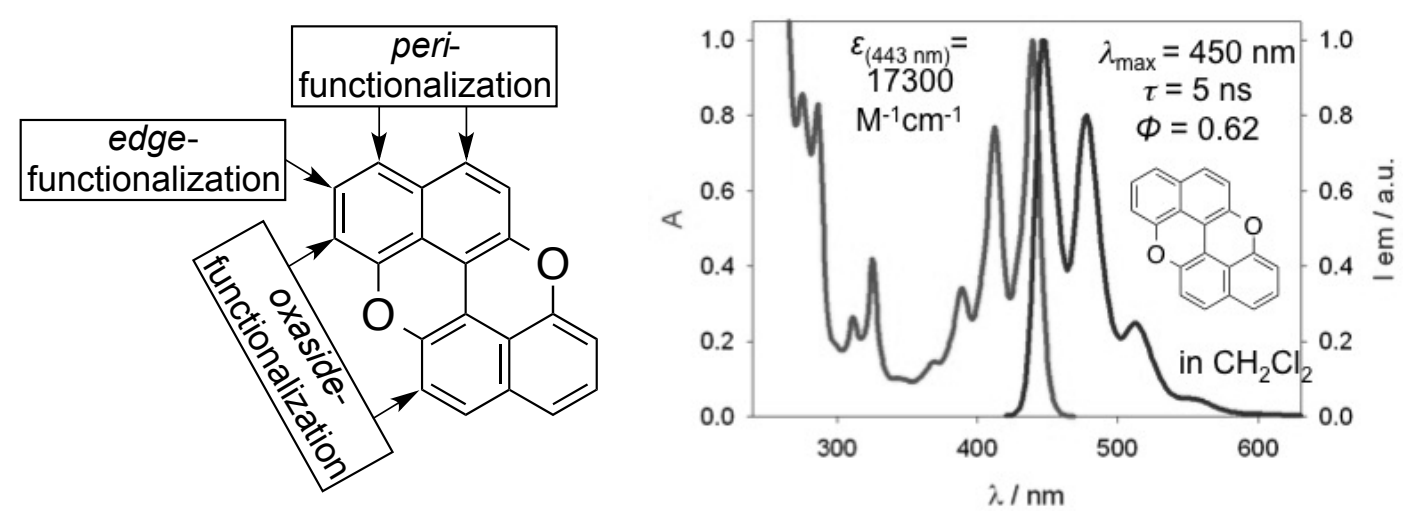

Figure 1. Structure of $\mathbf{P X X}$ and normalized absorption and emission spectra in $\mathrm{CH}_{2} \mathrm{Cl}_{2}$ at $r . t$.

Our group is interested in engineering heteroatom-doped polycyclic aromatic chromophores that are significant for optoelectronic applications.[16] One of our targets is peri-xanthenoxanthene (hereafter abbreviated $\mathbf{P x x}$ ), the o-doped analogue of anthanthrene (Figure 1).[16-20] Building on a high-yielding protocol, we synthesized $\pi$-extended versions of $\mathbf{P x x}$ and corroborated their 
electron donor properties by raising the HOMO energy level. [16] Considering the Vis-absorbing bandgap, with minor stokes shift and strong charge injection properties, ${ }^{[21]}$ we have considered that $\mathbf{P x x}$ could be an excellent chromophore to promote exergonic photoinduced single electron transfer (ET). Through the insertion of EWGs at the peri-positions (Figure 1), it is expected that one can tune the frontier orbital energy levels of $\mathbf{P x x}$, and thus the redox properties of its excited states. ${ }^{[22]}$ This conjecture led us to design structural mimics of the well-known perylene-diimide (PDI) ${ }^{[23]}$ molecules in which a PXX exposes either one (PXXMI) or two (PXXDI) electron-depleting alkylimide groups (Scheme 1). ${ }^{[23,24]}$ 
<smiles>O=C1OC(=O)c2cc(O)cc3cccc1c23</smiles>

1 a)<smiles>O=C1OC(=O)c2cc(O)c(Br)c3cccc1c23</smiles>

2 95\%

$\downarrow$ b)

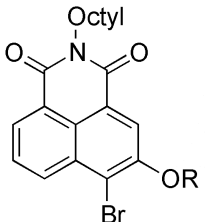

$3 \mathrm{R}=\mathrm{H} 97 \%$
$4 \mathrm{R}=$ Me quant. $\longleftarrow$ c)

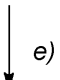

Octyl

$5 \mathrm{R}=\mathrm{Me} 49 \%$

$6 \mathrm{R}=\mathrm{H}$ quant.

h)

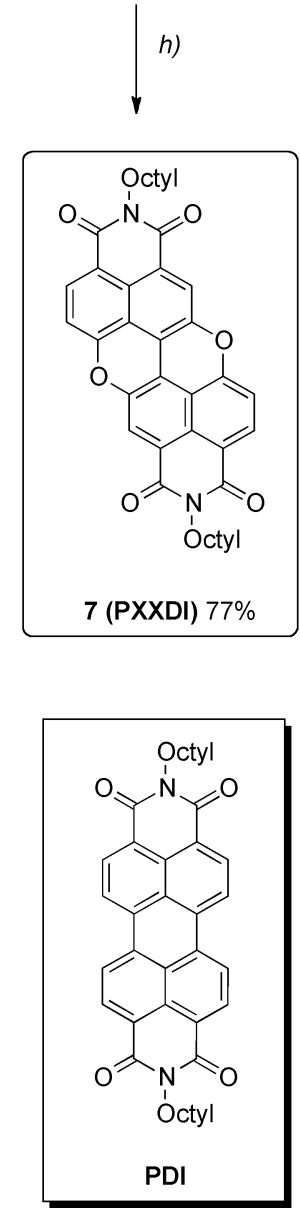

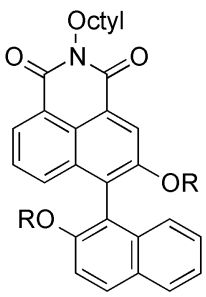

$8 \mathrm{R}=\mathrm{Me}$ 94\%

$9 \mathrm{R}=\mathrm{H} 97 \%$

i)

$\checkmark$

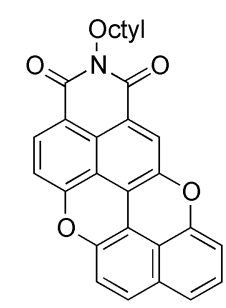

10 (PXXMI) 86\%

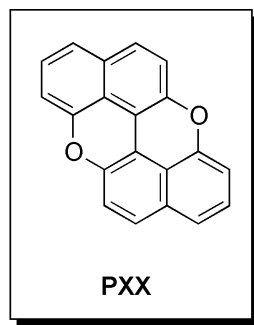

Scheme 1. a): Br, dioxane, reflux, 2.5h; b): DIPEA, n-octylamine, dioxane, reflux, 20h; c): $\mathrm{K}_{2} \mathrm{CO}_{3}, \mathrm{CH}_{3} \mathrm{I}, \mathrm{CH}_{3} \mathrm{CN}$, reflux, 4h; d): $\mathrm{Cs}_{2} \mathrm{CO}_{3}, \mathrm{~B}_{2} \mathrm{Pin} \mathrm{h}_{2}\left[\mathrm{Pd}(\mathrm{dba}){ }_{2}\right]$, SPhos, dioxane, reflux, 18h; e): $\mathrm{Cs}_{2} \mathrm{CO}_{3},\left[\mathrm{Pd}(\mathrm{dba})_{2}\right]$, SPhos, dioxane, reflux, 16h; f,g): $\mathrm{BBr}_{3}, \mathrm{CH}_{2} \mathrm{Cl}_{2}, 0^{\circ} \mathrm{C}$ to r.t., 16h; h,i): $\mathrm{PivOH}, \mathrm{CuI}, \mathrm{DMSO}, 120^{\circ} \mathrm{C}, 5 \mathrm{~h}$. 


\section{Results and discussion}

Synthesis. Our investigations commenced with the syntheses of 7 (PXXDI) and 10 (PXXMI) (Scheme 1). Regioselective bromination ${ }^{[25]}$ of hydroxyl-naphthalenyl derivative $\mathbf{1}$ gave anhydride $\mathbf{2}$, which could be transformed into 3. ${ }^{[26]}$ Subsequent methylation with MeI gave 4 with an overall yield of 92\%. 5 was obtained in 49\% yield by a two-step protocol including the in-situ preparation of the boronate derivative from $\mathrm{B}_{2} \mathrm{Pin}_{2}$ through Miyaura borylation reaction ${ }^{[27]}$ and subsequent Suzuki cross-coupling ${ }^{[28]}$ with bromoderivative 4 in the presence of [Pd(dba) 2$],$ SPhos, and $\mathrm{Cs}_{2} \mathrm{CO}_{3}$. ${ }^{[29]}$ Similarly, Suzuki cross-coupling of methoxy-naphthalenboronic acid with 4 gave $\mathbf{8}$ in $94 \%$ yield. ${ }^{[30]}$ Demethylation of $\mathbf{5}$ and $\mathbf{8}$ with $\mathrm{BBr}_{3}$ afforded binaphthols 6 and 9, respectively. CuI-promoted oxidative ring-closure ${ }^{[19]}$ of $\mathbf{6}$ and 9, gave target compounds PXXDI and PXXMI in 77\% (34\% over six steps) and 86\% (72\% over six steps) yield, respectively. $\mathbf{P X x}^{[19]}$ and reference molecule PDI $^{[31]}$ were also prepared.

Table 1. Photophysical data in aerated solvents at r.t.

\begin{tabular}{|c|c|c|c|c|}
\hline & \multicolumn{3}{|c|}{$\mathrm{C}_{6} \mathrm{H}_{6}$} & \\
\hline & Absorption & \multicolumn{3}{|c|}{ Emission } \\
\hline & $\left(\varepsilon, \quad \mathrm{M}^{-1} \mathrm{Cm}^{-1}\right)$ & $\begin{array}{c}\lambda_{\max } \\
(\mathrm{nm})\end{array}$ & $\stackrel{\tau}{\tau}[\mathrm{ns})^{[\mathrm{a}]}$ & $\Phi^{[\mathrm{b}]}$ \\
\hline $\mathrm{PXX}$ & $444 \quad(17500)$ & 449 & 5.0 & $0.71^{[c]}$ \\
\hline PXXMI & $524 \quad(17600)$ & 546 & 7.6 & 0.71 \\
\hline \multirow[t]{2}{*}{ PXXDI } & $539(35900)$ & 549 & 3.3 & 0.39 \\
\hline & \multicolumn{3}{|c|}{$\mathrm{CH}_{2} \mathrm{Cl}_{2}$} & \\
\hline $\mathrm{PXX}$ & $443(17300)$ & 450 & 5.0 & $0.62^{[c]}$ \\
\hline PXXMI & $525 \quad(17800)$ & 564 & 9.2 & 0.68 \\
\hline PXXDI & $538 \quad(43500)$ & 548 & 3.2 & 0.39 \\
\hline \multirow[t]{2}{*}{ PDI } & $524 \quad(75000)$ & 532 & 4.5 & 1.00 \\
\hline & \multicolumn{3}{|c|}{$\mathrm{CH}_{3} \mathrm{CN}$} & \\
\hline PXX & $439(-)$ & 447 & 5.1 & $0.60^{[\mathrm{c}]}$ \\
\hline PXXMI & $519(-)$ & 570 & 9.8 & 0.61 \\
\hline PXXDI & $535 \quad(-)$ & 548 & 3.4 & 0.34 \\
\hline
\end{tabular}

${ }^{[a]} \lambda_{\text {ex }}=372$ or $459 \mathrm{~nm} .{ }^{[\mathrm{b}]}$ Standard: Rhodamine $6 \mathrm{G}$ in EtoH $(\Phi$ 
$=0.94) .{ }^{[c]}$ Standard: coumarine 153 in EtOH $(\Phi=0.53)$.

Photophysical and electrochemical characterization. While PXX depicts the lowest energy electronic transition around $440 \mathrm{~nm}$ in $\mathrm{CH}_{2} \mathrm{Cl}_{2}$, PXXMI and PXXDI display red-shifted bands centered at 525 and $538 \mathrm{~nm}$, respectively (Figure 2a). These absorption features are very similar to those of PDI. [22] Consistently, the luminescence spectra of both PXXMI and PXXDI (Figure 2b) show analogous emission profiles and properties $(\Phi=0.7-0.4 ; \tau=3-9 \mathrm{~ns})$ to that of PDI. Similar properties were also measured in $\mathrm{CH}_{3} \mathrm{CN}$ and $\mathrm{C}_{6} \mathrm{H}_{6} \quad$ (Table 1$)$.
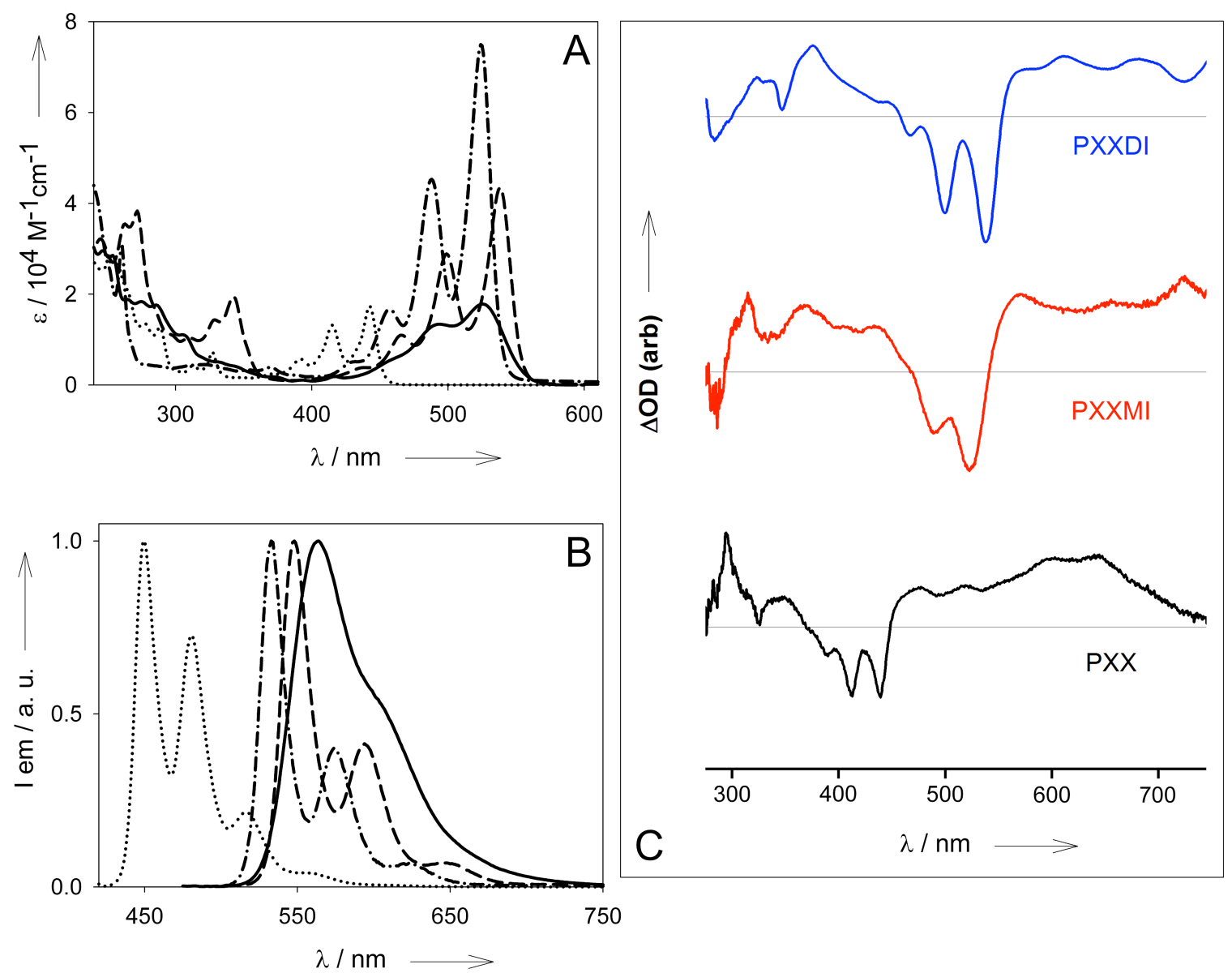

Figure 2. A) Absorption and B) normalized emission spectra of PXX (…), PDI (-··), PXXMI (-) and PXXDI (---) in air-equilibrated $\mathrm{CH}_{2} \mathrm{Cl}_{2}$ at r.t. $\left(\lambda_{\mathrm{ex}}=415,480\right.$, 488 and $466 \mathrm{~nm}$, respectively). C) Normalised transient absorption spectra of PXXDI (top), PXXMI (middle) and PXX (bottom) solutions in deaerated $\mathrm{C}_{6} \mathrm{H}_{6}$ $\left(\sim 1.0 \times 10^{-5} \mathrm{M}\right)$. The grey lines indicate $\triangle O D=0$ in each case. For PXXDI and PXXMI: $\lambda_{\text {pump }}=532 \mathrm{~nm}$; for Pxx: $\lambda_{\text {pump }}=355 \mathrm{~nm}$. TA spectra recorded 500 ns after photoexcitation.

Since no detectable phosphorescence was observed even at low 
temperatures, ${ }^{[20,21]}$ no precise determination of the energy of the triplet excited state is achieved. Nevertheless, we observed effective population of the excited triplet states for all three PXX derivatives by transient absorption spectroscopy (Figure 2c) in deaerated $\mathrm{C}_{6} \mathrm{H}_{6}$ (obtained through several freeze-pump-thaw cycles using $\mathrm{N}_{2}$ as the purge inert gas and a $10^{-4}$ bar vacuum) upon excitation at $355 \mathrm{~nm}$ (PXX) and $532 \mathrm{~nm}$ (PXXMI-PXXDI) . $\mathrm{C}_{6} \mathrm{H}_{6}$ was chosen as the solvent, considering the high solubility of the three dyes. Under these conditions, nanosecond resolved temporal decay of the excited triplet states exhibit exponential kinetics, concomitant with restoration of the respective photobleached ground states with averaged lifetimes of ca. $35 \mu \mathrm{s}$ for Pxx and 50 us for PXXMI and PXXDI (Figures S34-S35, SI). No qualitative differences in spectra were observed when PXXMI or PXXDI were pumped at $\lambda_{\mathrm{ex}}=355 \mathrm{~nm}$. As expected, recovery times are heavily affected by the presence of $\mathrm{O}_{2}$ in solution (Figure S36, SI), [20] with estimated quenching constants greater than $3 \times 10^{8} \mathrm{M}^{-1} \mathrm{~s}^{-1}$ both for PXXMI and PXXDI.

Cyclic voltammetry (CV) was used to assess the redox properties of the PXX derivatives (Figures S39-S42, SI). As it clearly appears from Table 2, the insertion of one (PXXMI) and two (PXXDI) imides increases the oxidative character $\left(E^{1 / 2}\right.$ red $=-1.87$ and $-1.54 \mathrm{eV} \mathrm{vs}$. $\mathrm{FC}^{+} / \mathrm{FC}$ in $\mathrm{ODCB}$, respectively) and lessens the reductive properties $\left(E^{1 / 2}\right.$ ox $=0.63$ and $0.92 \mathrm{eV}$ in ODCB, respectively) of $\mathbf{P x x} .{ }^{[17]}$ The reference molecule PDI displays the strongest oxidizing character, with two reductions at -1.16 and $-1.34 \mathrm{eV}$. [32] Similar redox properties were also measured in $\mathrm{CH}_{3} \mathrm{CN}$ and $\mathrm{CH}_{2} \mathrm{Cl}_{2}$, suggesting a negligible effect of the solvent polarity on the reduction and oxidation potential values.

From the combination of photophysical and redox properties, it results that the redox potentials of the singlet excited states are conveniently shifted by insertion of the imide subunits (Figure 3) and, most notably, PXXMI and PXXDI are respectively stronger reducer and oxidizer at their singlet excited states compared to the triplet state of the widely employed complex 
$\left[\mathrm{Ru}(\mathrm{bpy})_{3}\right]^{2+}$. On the other hand, the singlet excited state of $\mathbf{P x x}$ is both a greater oxidizer and reducer with respect to the triplet state of [Ir(ppy)3]. These data prompted us to consider the use of these new PXX derivatives to trigger chemical reactions.

Table 2. $\mathrm{CV}$ data in $\mathrm{ODCB}, \mathrm{CH}_{2} \mathrm{Cl}_{2}$ and $\mathrm{CH}_{3} \mathrm{CN}$ at r.t. Peak separations in $\mathrm{mV}$ are indicated in brackets. Right: LUMO and HOMO orbitals calculated at the B3LYP/6-31G* level of theory.

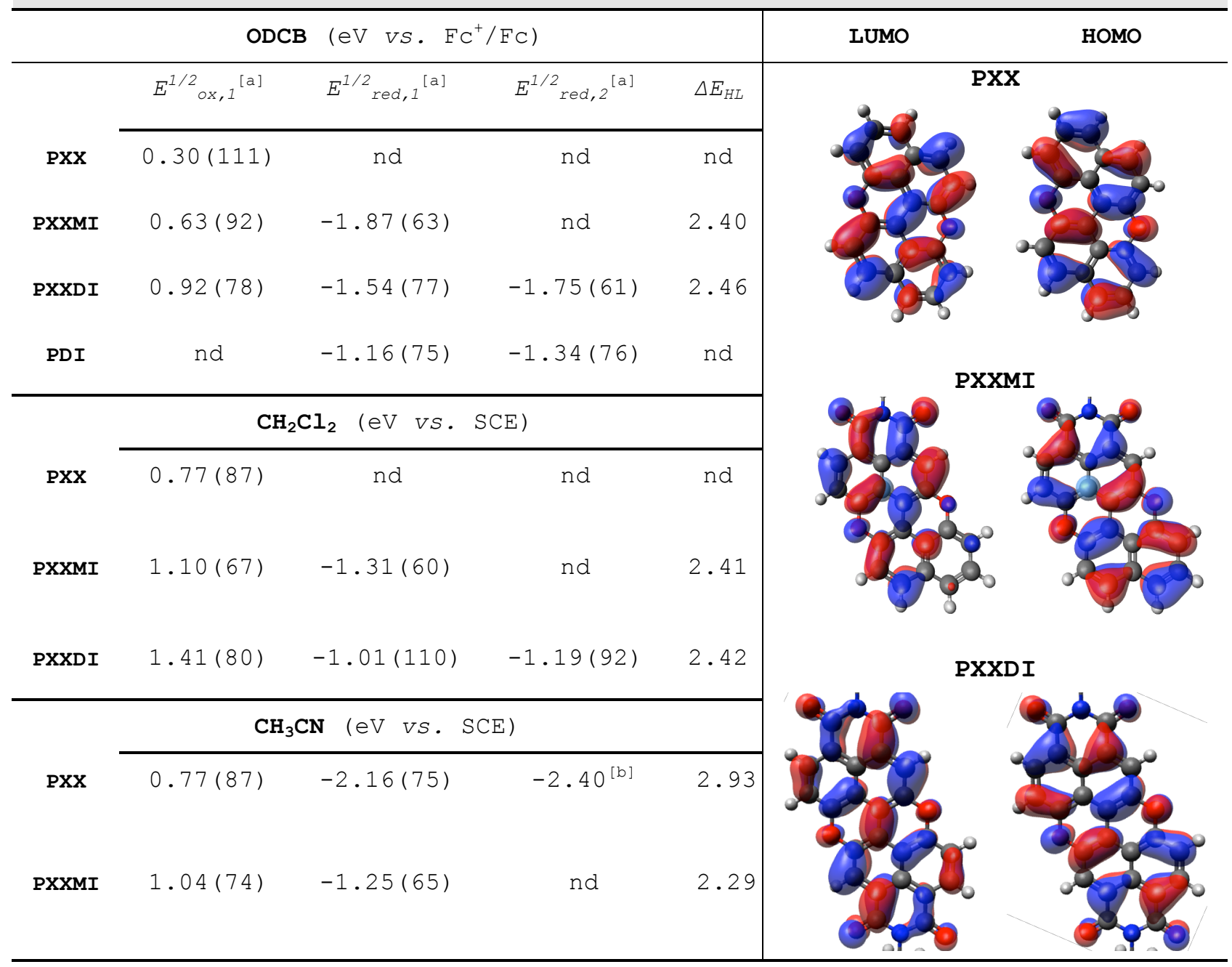

${ }^{[a]}$ Halfwave potentials unless differently specified. ${ }^{[b]}$ Peak potential. "nd" stands for "not detected". 


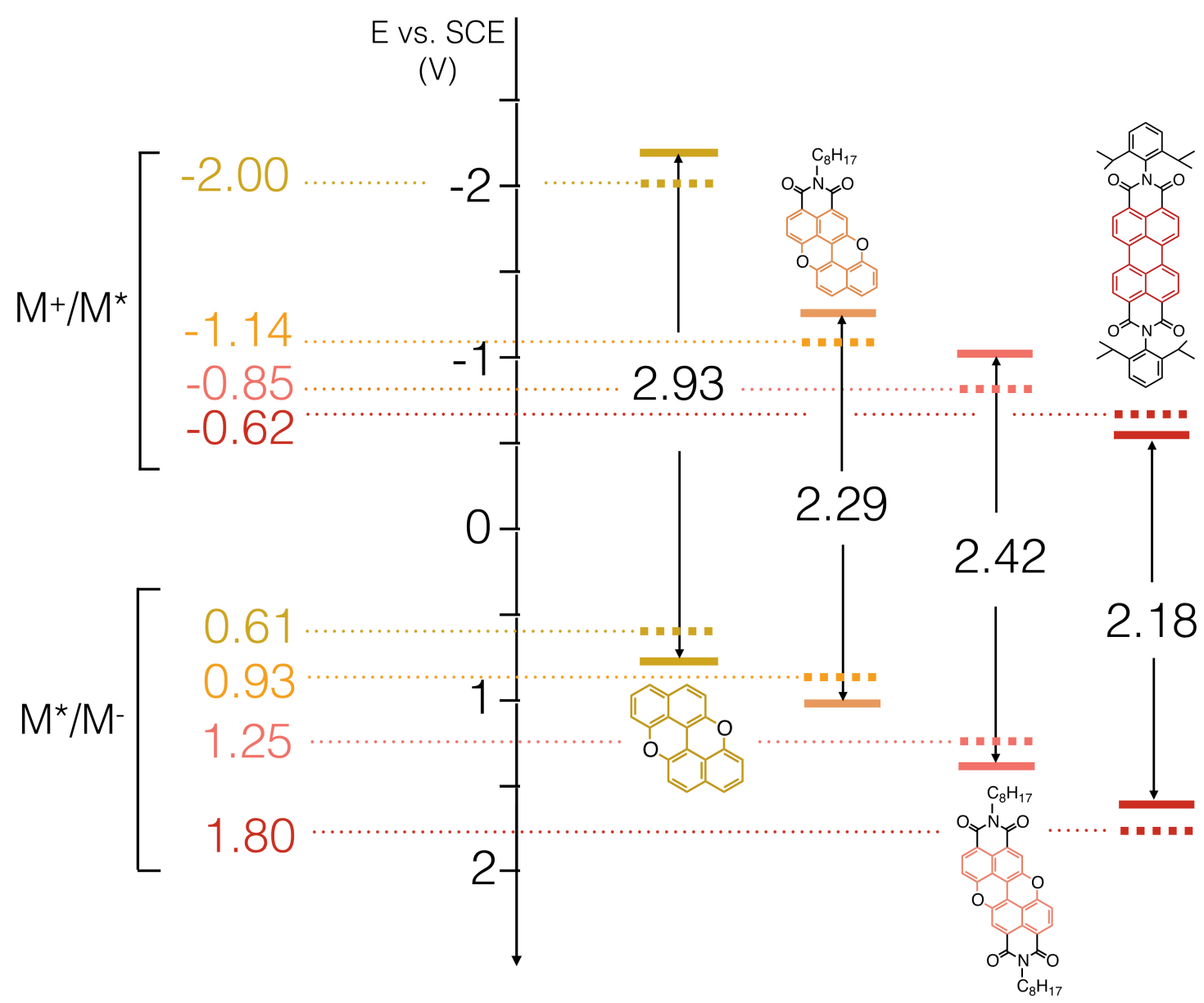

Figure 3. HOMO and LUMO energy levels of PXX, PXXMI, PXXDI, and PDI-diphenyl, [32] in $\mathrm{CH}_{3} \mathrm{CN}$ (except for PXXDI and PDI-diphenyl that were estimated in $\mathrm{CH}_{2} \mathrm{Cl}_{2}$ and $\mathrm{CH}_{3} \mathrm{CN}: \mathrm{CHCl}_{3}$, respectively). Dashed lines: reduction $\left(\mathrm{M}^{+} / \mathrm{M}^{*}\right)$ and oxidation $\left(\mathrm{M}^{*} / \mathrm{M}^{-}\right)$ potentials of the singlet excited states.

Phototriggering chemical dehalogenation reactions. We focused our attention on the dehalogenation ${ }^{[33,34]}$ as a model transformation (Table 3) which can be triggered by photoinduced electron transfer to and from the different PXX derivatives. For example, when irradiating a degassed solution of $\mathrm{PhCOCH}_{2} \mathrm{Br}$ at $520 \mathrm{~nm}$ in the presence of DIPEA and either PXX, PXXMI or PXXDI, full conversion of $\mathrm{PhCOCH}_{2} \mathrm{Br}$ into $\mathrm{PhCOCH}_{3}$ was observed by GC-MS analysis (Table 3, entry 1$)$ after $24 \mathrm{~h}$ in $\mathrm{CH}_{3} \mathrm{CN}(\varepsilon=35.9)$. Full conversion was also obtained in $\mathrm{CH}_{2} \mathrm{Cl}_{2}(\varepsilon=8.93)$ and $\mathrm{C}_{6} \mathrm{H}_{6}(\varepsilon=2.28)$, clearly indicating that the chemical nature of the radical intermediates is insensitive to the polarity of the solvents (details in Table S4, SI). It is worth noting that GC-analysis of the aforementioned mixtures often show, even in mixtures kept in the dark, the presence of unidentified peaks (not taken into account for the 
conversion determination), likely corresponding to undesirable byproducts formed as a consequence of the reactivity of the residual amount of nitroxides present in the DIPEA towards the halogeno-substrates.

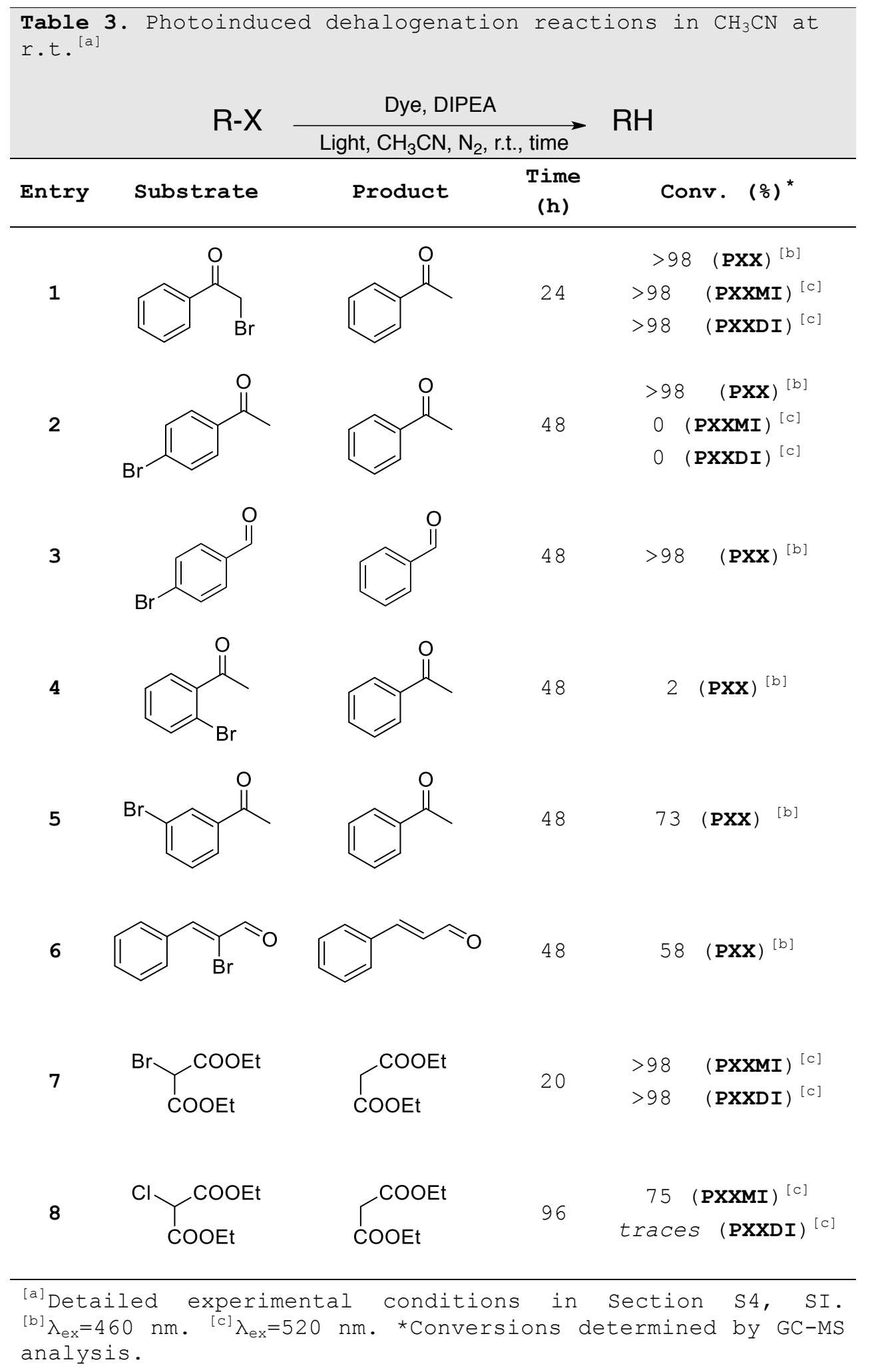


Notably, tiny crystals suitable for X-ray diffraction spontaneously formed during the dehalogenation reaction of $\mathrm{PhCOCH}_{2} \mathrm{Br}$ in $\mathrm{C}_{6} \mathrm{H}_{6}$ (details in section $\mathrm{S} 6$, SI). To our surprise, $\mathrm{X}-$ ray analysis showed that the crystal structure corresponded to that of the $\left[\mathrm{H}_{2} \mathrm{~N}^{\mathrm{i}} \mathrm{Pr}_{2}\right] \mathrm{Br}$ salt (Scheme 2). Furthermore, both PXXMI and PXXDI can access the photoreduction of diethylbromomalonate (DEBM) and the consequential quantitative dehalogenation after 20 h (Table 3, entry 7). Notably, when reacted with diethylchloromalonate (DECM), only PXXMI effectively triggers the dehalogenation (Table 3, entry 8). Conversely, when reacted with aromatic halides, none of the imide-based colorants gave any conversion. Only PXX under irradiation at $460 \mathrm{~nm}$ prompted the transformation and, more specifically, quantitative dehalogenations of p-bromoacetophenone $\left(p \mathrm{Br}-\mathrm{Ar} \mathrm{COCH}_{3}\right)$ and $p-$ bromobenzaldehyde (pBr-ArCOH) were observed after 48 h (Table 3, entries 2-3) in $\mathrm{CH}_{3} \mathrm{CN}$. Notably, low conversion was observed for $\mathrm{pBr}-\mathrm{ArCOH}$ in $\mathrm{CH}_{2} \mathrm{Cl}_{2}$ and negligible conversion was observed in $\mathrm{C}_{6} \mathrm{H}_{6}$. These results suggest that for aromatic substrates, key charge radical intermediates are likely formed and thus better stabilized in polar solvents (see Tables 55 and $\mathrm{S} 8$, SI). In $\mathrm{CH}_{3} \mathrm{CN}$, whilst the meta derivative gave good conversion (Table 3, entry 5), negligible dehalogenation was observed for the ortho isomer (Table 3, entry 4).

\section{Spectroscopic investigations of the reaction mechanism. The} substrate-dependent photoreactivity of the diverse PXX derivatives engendered a mechanistic study, by means of which we could disclose more in depth the chemical properties of the photogenerated radical intermediates during their transformation. Stern-Volmer analysis ${ }^{[35]}$ (Table 4) showed that the fluorescence quenching rates observed for derivatives PXXMI and PXXDI with $\mathrm{PhCOCH}_{2} \mathrm{Br}\left(k_{\mathrm{q}}=2.2 \times 10^{8}\right.$ and $4.5 \times 10^{8} \mathrm{M}^{-1} \mathrm{~S}^{-1}$, respectively $)$ are considerably lower than those determined with DIPEA $\left(k_{q}=4.2 \times 10^{9}\right.$ and $5.8 \times 10^{9} \mathrm{M}^{-1} \mathrm{~S}^{-1}$ ) in $\mathrm{CH}_{3} \mathrm{CN}$. This suggests that, under illumination, PXXMI $^{--}$and PXXDI $^{\boldsymbol{O}^{-}}$are likely formed through oxidation of DIPEA into $\operatorname{DIPEA}^{\bullet+}$ (Scheme 2). 


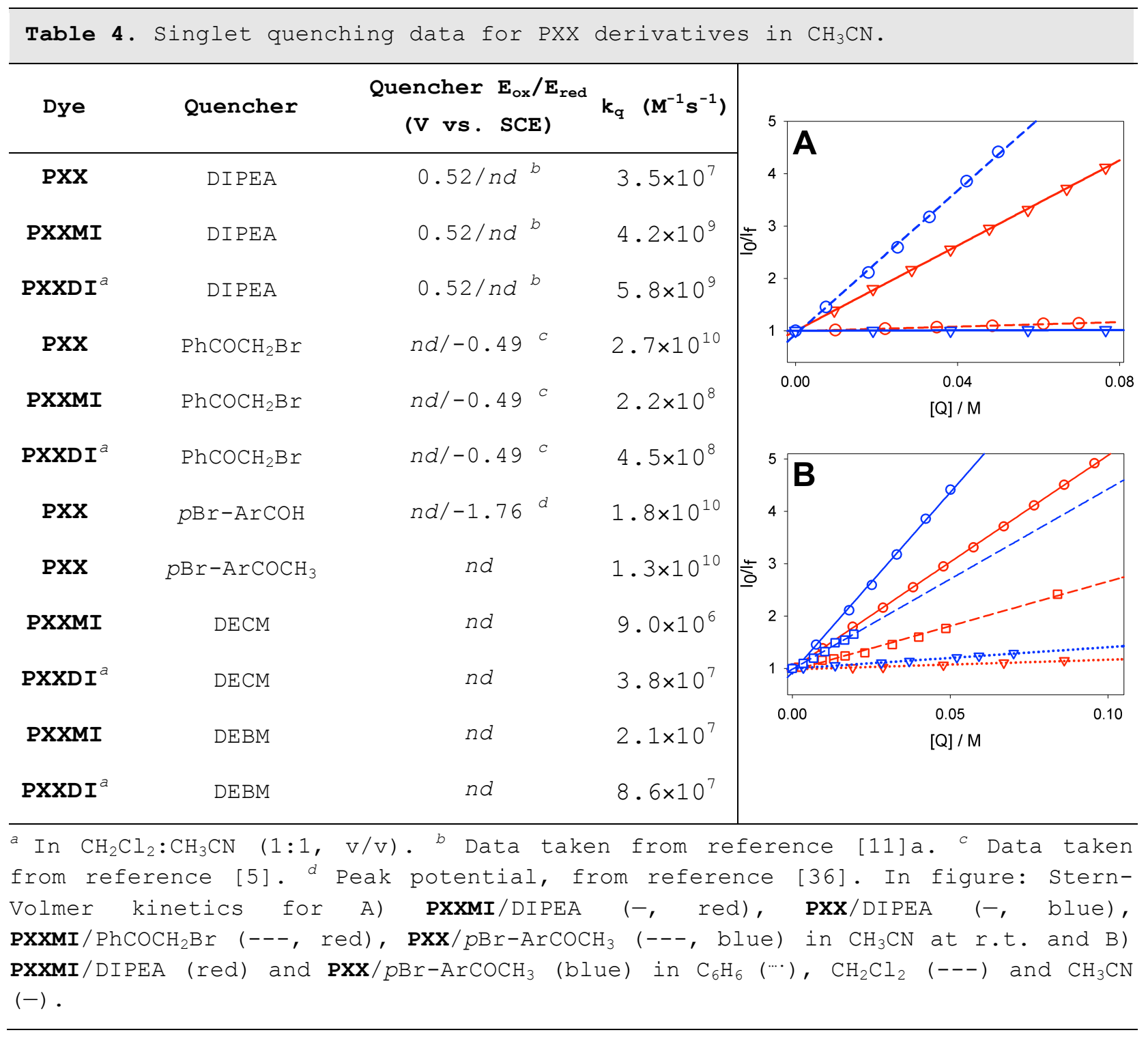

Considering that the reaction also occurs in an apolar solvent like $\mathrm{C}_{6} \mathrm{H}_{6}$, it is reasonable to assume that $\mathrm{PhCOCH}_{2} \mathrm{Br}$ reacts with either $\mathbf{P X X M I}^{{ }^{-}}$or $\mathbf{P X X D I}^{--}$to give the neutral phenacyl radical $\mathrm{PhCOCH}_{2}{ }^{\cdot}$ and $\mathrm{Br}^{-}$following a concerted dissociative ET mechanism. [37] $\mathrm{PhCOCH}_{2}{ }^{\cdot}$ successively reacts with $\mathrm{DIPEA}^{\bullet+}$ through hydrogen-atom transfer (HAT) ${ }^{[15]}$ leading to $\mathrm{PhCOCH}_{3}$ and the relevant iminium, which is hydrolyzed into the $\left[\mathrm{H}_{2} \mathrm{~N}^{i} \mathrm{Pr}_{2}\right] \mathrm{Br}$ salt and $\mathrm{CH}_{3} \mathrm{CHO}$. The crystallization of $\left[\mathrm{H}_{2} \mathrm{~N}^{i} \mathrm{Pr}_{2}\right] \mathrm{Br}$ in $\mathrm{C}_{6} \mathrm{H}_{6}$ suggests that the HAT occurs solely at the methylene site of DIPEA (Scheme 2). Given the reactivity of $\mathrm{PhCOCH}_{2}{ }^{\circ}$, one should also consider that the HAT could occur with DIPEA forming $\mathrm{CH}_{3}{ }^{\circ} \mathrm{CHN}^{i} \mathrm{Pr}_{2}$. Being a strongly reducing species, ${ }^{[38]} \mathrm{CH}_{3}{ }^{\circ} \mathrm{CHN}^{i} \mathrm{Pr}_{2}$ can in principle reduce $\mathrm{PhCOCH}_{2} \mathrm{Br}$ to yield 
$\mathrm{PhCOCH}_{2}{ }^{\circ}$ and the corresponding iminium, thereby self-propagating the reaction in a radical chain fashion (Scheme 2). [39] Control experiments in aerated solutions did not show any significant conversion to acetophenone or other dehalogenated species, suggesting that the presence of $\mathrm{O}_{2}$ (both at the triplet ground state and at its singlet excited state) is detrimental to the evolution of the radical mechanism as depicted in Scheme 2. ${ }^{[40]}$ Furthermore, we expect that, given their slow deactivation in deaerated solvents (around $50 \mu \mathrm{s}$ in $\mathrm{C}_{6} \mathrm{H}_{6}$ for PXXMI and PXXDI), the triplet excited states of imide-derivatives could also contribute to some extent to trigger the same transformation via an ET process. Preliminary triplet quenching analysis for PXXMI in the presence of DIPEA (Figure S37, SI) gave lower (two-orders of magnitude) quenching constants compared to those determined for singlet state quenching, while no significant variations were observed for the lifetime of the triplet state of PXXDI (Figure S38, SI). Taking all this information together, this data suggests that under these conditions, the triplet excited states of PXXMI and PXXDI do not significantly take part to the reaction mechanism.

Concerning PXx, Stern-Volmer studies (Figure $4 \mathrm{a}$ and Table S1, SI) showed that the quenching rate with $\mathrm{pBr}-\mathrm{ArCOCH}$ is considerably higher $\left(k_{\mathrm{q}}=1.3 \times 10^{10} \mathrm{M}^{-1} \mathrm{~s}^{-1}\right)$ than that determined with DIPEA $\left(k_{\mathrm{q}}=\right.$ $3.5 \times 10^{7} \mathrm{M}^{-1} \mathrm{~S}^{-1}$ ) in $\mathrm{CH}_{3} \mathrm{CN}$. As expected, lower quenching rates were observed in apolar solvents $\left(k_{\mathrm{q}}=6.9 \times 10^{9}\right.$ and $8.2 \times 10^{8} \mathrm{M}^{-1} \mathrm{~s}^{-1}$ in $\mathrm{CH}_{2} \mathrm{Cl}_{2}$ and $\mathrm{C}_{6} \mathrm{H}_{6}$, respectively, Figure 4b). Compared to the imide derivatives, this data suggests that the radical cation $\mathbf{P x x}^{{ }^{+}}$is likely formed with the concomitant reduction of $\mathrm{pBr}-\mathrm{ArCOCH}_{3}$ into a ketyl radical anion intermediate, ${ }^{[41]}$ the latter being stabilized in polar solvents (Scheme 2). This likely undergoes fragmentation by dissociative ET, producing an aryl radical ${ }^{\circ} \mathrm{ArCOCH}_{3}$ and $\mathrm{Br}^{-}$ anion. ${ }^{[42]}$ In the envisaged mechanistic scheme, $\mathbf{P x x}^{\bullet+}$ reacts with DIPEA to give $\mathrm{DIPEA}^{*+}$, the latter possibly reacting with ${ }^{\cdot} \mathrm{ArCOCH}_{3}$ through hydrogen-atom transfer (HAT) to give $\mathrm{PhCOCH}_{3}$ and the relevant iminium. Notably, the ketyl intermediate cannot be formed 
by direct reduction with $\mathrm{CH}_{3}{ }^{\circ} \mathrm{CHN}^{i} \mathrm{Pr}_{2}$, as this would have also occurred in the photosystems involving PXXMI and PXXDI. Photodegradation under laser excitation at $355 \mathrm{~nm}$, along with pBrArCOH absorption, prevented the garnering of information on the activity of the excited triplet state of $\mathbf{P X X}$.


C)

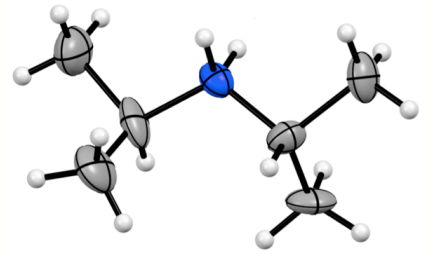<smiles>CC(=O)c1ccc(Br)c(Br)c1</smiles>

Scheme 2. Proposed photooxidative (A, for PXXMI/PXXDI) and photoreductive (B, for PXX) mechanisms. The crystal structure of $\left[\mathrm{H}_{2} \mathrm{~N}^{i} \mathrm{Pr}_{2}\right] \mathrm{Br}$ is also shown (C; details in Figure S43, SI). Color atoms: C grey, $N$ blue, Br yellow. Alkyl (R') and aromatic (A ${ }^{*}$ ) radicals have been detected through EPR experiments; the amino-radical intermediates have been hypothesized following the formation of the $\left[\mathrm{H}_{2} \mathrm{~N}^{i} \mathrm{Pr}_{2}\right] \mathrm{Br}$ byproduct. The formation of the ketyl radical anion intermediate for the p-bromoacetophenone has been proposed following reference [41].

To corroborate the mechanisms, EPR measurements were performed to identify the presence of the relevant radicals (Figures 4-6). Given the concentration requirements $\left(>10^{-3} \mathrm{M}\right)$ to obtain high signal-to-noise ratios, $\mathrm{CH}_{2} \mathrm{Cl}_{2}$ solutions were used. Deaerated mixtures containing i) PXXMI, DIPEA and $\mathrm{PhCOCH}_{2} \mathrm{Br}$ and ii) PXX, 
DIPEA and pBr-ArCOH, were analyzed in the dark and under irradiation, both in the absence and presence of the $\alpha$-phenyl-Ntert-butylnitrone (PBN) spin trap. CW $X$-band EPR spectra of both reaction mixtures, kept in the dark in the absence of PBN (Figures 4a-5a), reveal the presence of nitroxyl radicals $\mathbf{N 1}^{\bullet}$ and $\mathbf{N}^{*}$, both possibly derived from the dealkylation of trace DIPEA-N-oxide ${ }^{[43]}$ (Figure S44, SI). Upon irradiation, the same signals display a steep increase in intensity, reaching a maximum which is likely caused by the consumption of residual trace $\mathrm{O}_{2} \cdot{ }^{[44]}$ Then, a decrease in signal intensity is detected within a few seconds, possibly due to the scavenging of the paramagnetic $\mathbf{N}^{\cdot}$ and $\mathbf{N}^{\cdot}{ }^{\cdot}$ species by radical recombination and/or by quenching of the excited states of the dye. This suggests that the nitroxides could extinguish the photoinduced dehalogenation reaction ${ }^{[45]}$ (Figure 6b, depicting the variation of the EPR signal as a function of the irradiation time for mixture ii; see also details in Figures S49-S50, SI). Indeed, after this time lapse, a new series of signals started to appear in the EPR spectra. These can be readily assigned to the photogenerated radicals $\mathbf{P h}-\mathbf{N} \mathbf{2}^{\cdot}$ and $\mathbf{A r}-\mathbf{N} 2^{\circ}$, for mixtures $i$ and $i$, respectively (Figures 4b-5b, details in Figures S45-S46, SI). When irradiated in the presence of PBN (Figure 6a), a spectrum composed of a triplet of 1:1 doublets also appeared together with the previous signals for both reactions. These EPR signals can be unambiguously assigned to the nitroxyl radicals $\mathbf{P h}-\mathbf{S T}^{\cdot}$ and $\mathbf{A r}-\mathbf{S T}^{*}$, the latter derived from the reaction of PBN with the photogenerated radicals $\mathrm{PhCOCH}_{2}{ }^{\cdot}$ (Figure $4 \mathrm{C}$ ) and ${ }^{\cdot} \mathrm{ArCOCH}_{3}$ (Figure 5c) in mixtures $i$ and $i$, respectively (details in Figures S47-48, SI). For mixture ii, evolution of the signal corresponding to Ar$\mathbf{S T}^{\cdot}$ as a function of the irradiation time is depicted in Figure 6a, displaying a steady increase after ca. 180' of irradiation, suggesting the formation of $\mathbf{A r}^{\cdot}$ and thus, the progression of the dehalogenation. 

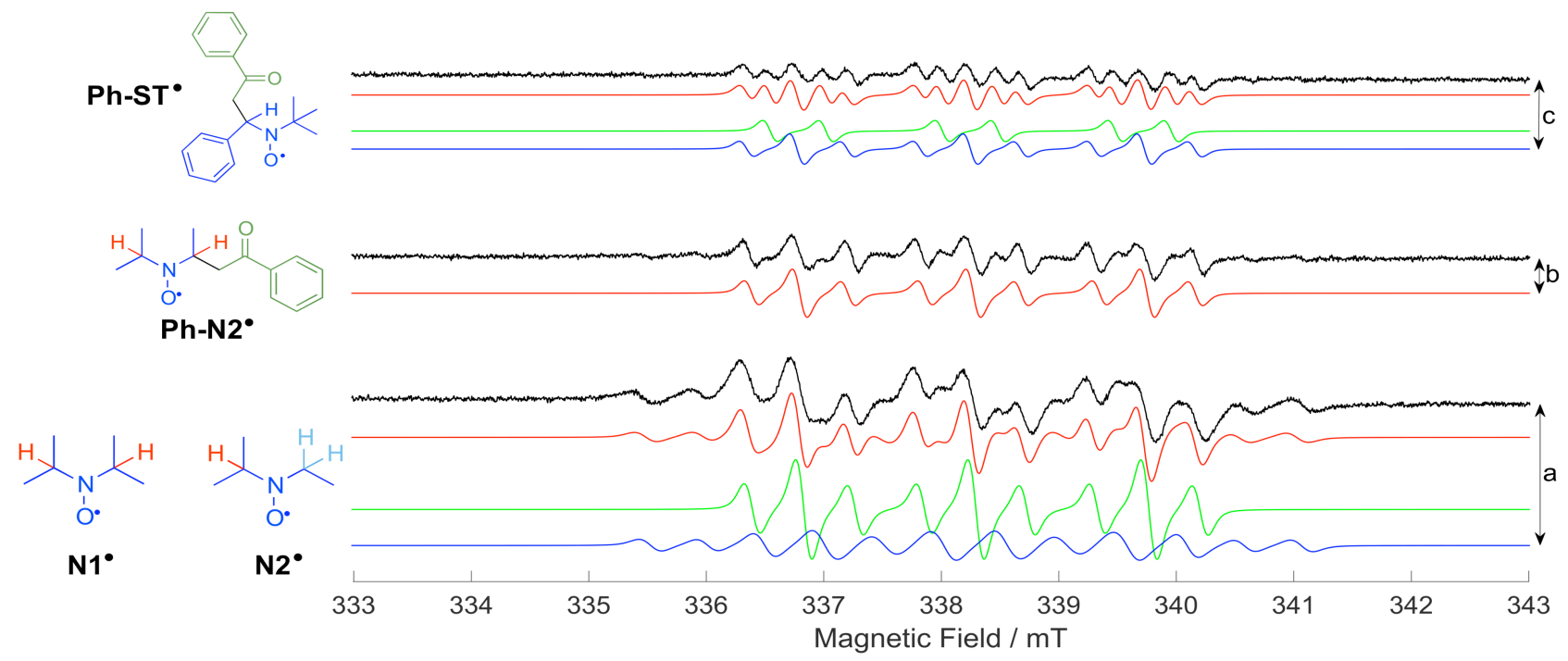

Figure 4. CW X-band EPR spectra (black traces) recorded at $298 \mathrm{~K}$ for $\mathrm{CH}_{2} \mathrm{Cl}_{2}$ solutions of $\mathrm{PhCOCH}_{2} \mathrm{Br}(0.05 \mathrm{M})$, DIPEA $(0.40 \mathrm{M})$ and PXXMI (2.5 mM), before (a) and after ca. 50' (b) of irradiation ( $\lambda_{e x}=530 \mathrm{~nm}$ ) both in the absence (b) and presence (c) of PBN. EPR simulations are shown in red. The deconvoluted simulated spectra of radicals $\mathbf{N}^{*}$ and $\mathbf{N}^{*}$ are shown in green and blue respectively in a), whilst the deconvoluted simulated spectra of the $\mathbf{P h}^{\mathbf{S}} \mathbf{T}^{\bullet}$ adduct and $\mathbf{P h}-\mathbf{N} \mathbf{2}^{\circ}$ radicals are shown in green and blue respectively in $\mathrm{C}$ ).

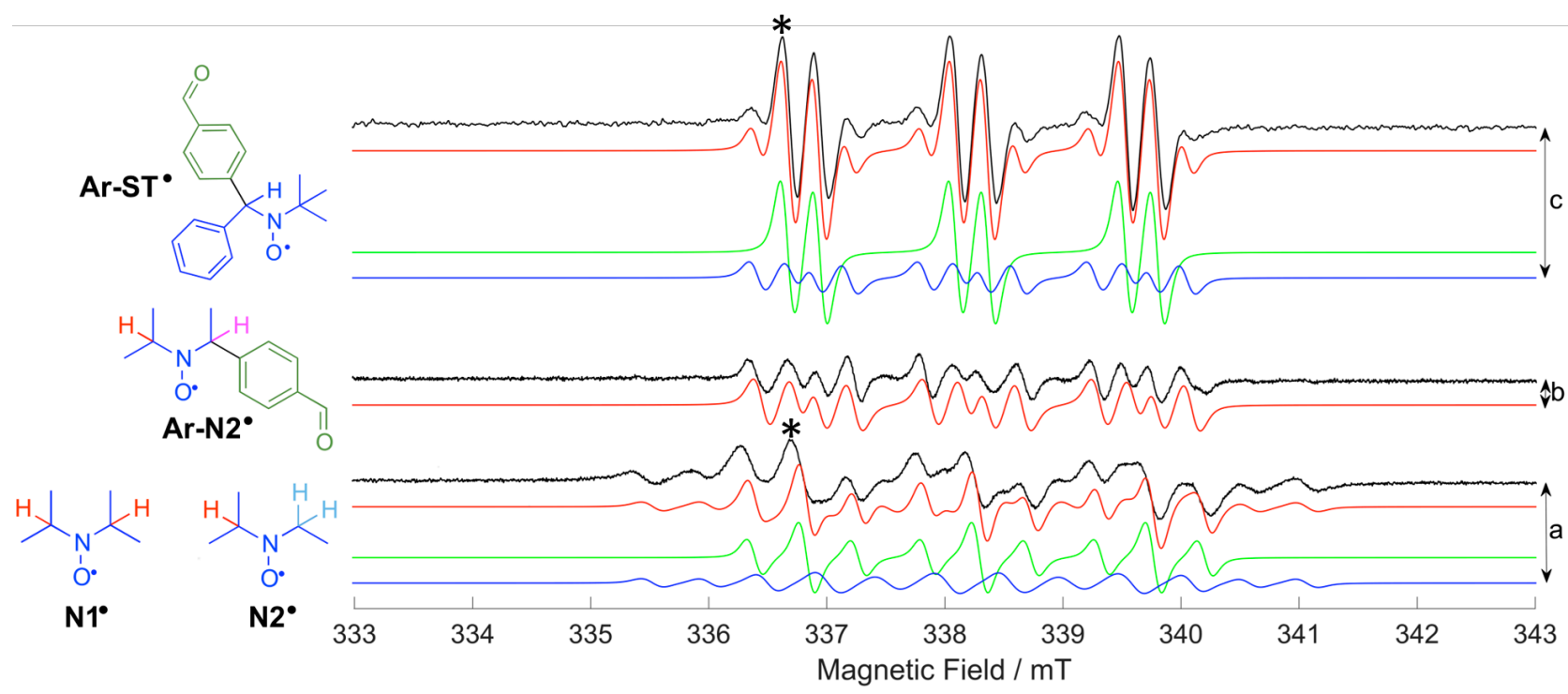

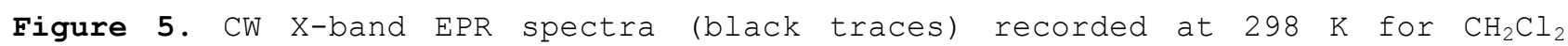
solutions of pBr-ArCOH (0.05 M), DIPEA (0.40 M) and PXX (2.5 mM), before (a) and after 50' (b) of irradiation ( $\lambda_{\mathrm{ex}}=455 \mathrm{~nm}$ ) both in the absence (b) and presence (c) of PBN. EPR simulations are shown in red. The deconvoluted simulated spectra of $\mathbf{N 1}^{*}$ and $\mathbf{N}^{*}$ are reported in green and blue respectively in a), whilst those of

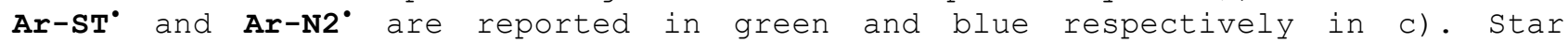
indicates the magnetic field monitored during the kinetical analysis. 


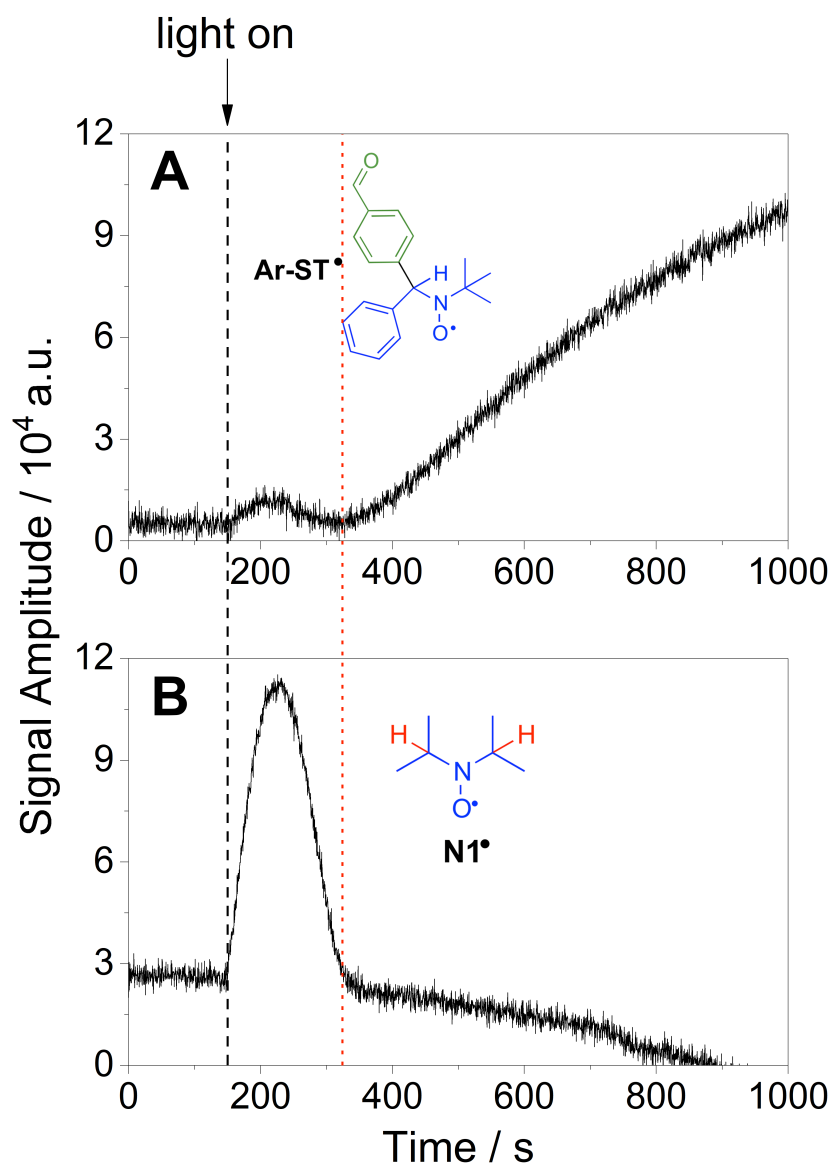

Figure 6. Evolution of the EPR signal intensity as a function of the irradiation time $\left(\lambda_{\text {ex }}=455 \mathrm{~nm}\right)$ taken at $336.6 \mathrm{mT}$ in the presence of PBN (A) and at $336.7 \mathrm{mT}$ in the absence of PBN (B) for a solution containing PXx, DIPEA and $p-$ bromobenzaldehyde in $\mathrm{CH}_{2} \mathrm{Cl}_{2}$. Black line indicates the start of the irradiation; red line indicates the start of the production of the $\mathbf{A r}-\mathbf{S T}^{*}$ radical.

Building on this mechanistic insight, one could imagine triggering chemoselectively the dehalogenation of distinctive C-Br groups, sequentially using green and blue light. In principle, this would give access to chemoselective transformations (alkyl or aromatic halide species) on the same substrate. This is a crucial issue in the efficient synthesis of fine chemicals and pharmaceuticals as well as in multistep and multicomponent reactions. To prove this principle, we considered the use of 2,4'-dibromoacetophenone (pBrArCOCH${ }_{2} \mathrm{Br}$, Scheme 3), featuring two C-Br bonds having different reactivities.<smiles>O=C(CBr)c1ccc(Br)cc1</smiles><smiles>CC(=O)c1ccc(Br)cc1</smiles>

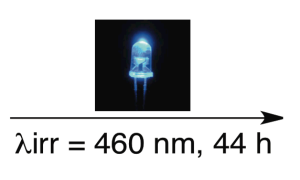<smiles>CC(=O)c1ccccc1</smiles>

Scheme 3. Photo-triggered chemoselective dehalogenation in deaerated $\mathrm{CH}_{3} \mathrm{CN}$, in the presence of $\mathbf{P X X}$ and PXXMI (5\% mol). 
When a solution of $\mathrm{B} r-\mathrm{ArCOCH} \mathrm{C}_{2} \mathrm{Br}$, DIPEA, PXX and PXXMI was irradiated with green light for $30 \mathrm{~h}$, the $\alpha$-dehalogenated product could be selectively obtained. Subsequent irradiation with blue light for $44 \mathrm{~h}$ quantitatively afforded $\mathrm{PhCOCH}_{3}$. Given the low concentration of the dyes (5\% mol), we can consider that in the mixture each chromophore acts orthogonally upon its selective excitation following the mechanisms proposed in scheme 2. The mutual quenching between the two chromophores has been found to be efficient in the case of the singlet excited state of PXXMI, with a constant approaching the diffusion limit $\left(\sim 2.5 \times 10^{10} \mathrm{M}^{-1} \mathrm{~s}^{-1}\right.$, Figure S32, SI). However, in the presence of an excess of DIPEA (ca. $0.25 \mathrm{M})$ only 3\% of singlet excited states of PXXMI can be effectively intercepted by $\mathbf{P x x}$ (see note in the SI below Figure S32). To corroborate these assumptions, we perform the dehalogenation reactions under more diluted conditions (0.42 mM). As expected, the desired sequence of products could be obtained although with lower conversion (Table S12, SI).

\section{Conclusions}

In summary, we have succeeded in synthesizing a new series of PXX derivatives in which the energy levels of the excited states have been tailored through the insertion of imide groups. This allowed the syntheses of new photoredox active chromophores, with redox potentials of the singlet excited states comparable to those of widely used inorganic triplet photocatalysts such as [Ru(bpy) $]^{2+}$ and [Ir(ppy) 3$]$. Capitalizing on the dehalogenation of organic halides as a model reaction, we could propose the oxidative and reductive mechanistic pathways controlling a specific transformation in the presence of the relevant dye. Given the contemporary importance of finding sustainable methodologies in organic chemistry, this work demonstrates that the expansion of the chemical space of photoinduced organic transformations and the study of their mechanism should also pass through the development of chromophores featuring tailored photoredox properties. 


\section{Acknowledgements}

D.B. gratefully acknowledges the EU through the ERC Starting Grant "COLORLANDS" project, the MC-ITN ETN network "PHOTOTRAIN" and Cardiff University. We thank Prof. Dr. Simon Pope (Cardiff University) for the access to the time-resolved measurements.

\section{Keywords}

Polycyclic aromatic hydrocarbons; heteroatom doping; photoinduced electron transfer; photoreaction; photoredox active dyes.

\section{Notes and references}

[1] a) M. Stepień, E. Gońka, M. Żyła, N. Sprutta, Chem. Rev. 2017, 117, 3479-3716; b) A. Narita, X. Wang, X. Feng, K. Müllen, Chem. Soc. Rev. 2015, 44, 6616-6643; c) X. Wang, G. Sun, P. Routh, D. Kim, W. Huang, P. Chen, Chem. Soc. Rev. 2014, 43, $7067-7098$.

[2] D. A. Nicewicz, D. W. C. MacMillan, Science 2008, 322, 77-80.

[3] N. A. Romero, D. A. Nicewicz, Chem. Rev. 2016, 116, 1007510166 .

[4] D. Ravelli, M. Fagnoni, A. Albini, Chem. Soc. Rev. 2013, 42, 97-113.

[5] M. Neumann, S. Füldner, B. König, K. Zeitler, Angew. Chem. Int. Ed. 2011, 50, 951-954.

[6] a) E. Arceo, I. D. Jurberg, A. Álvarez-Fernández, P. Melchiorre, Nat. Chem. 2013, 5, 750-756; b) J. J. Murphy, D. Bastida, S. Paria, M. Fagnoni, P. Melchiorre, Nature 2016, $532,218-222$.

[7] a) C. K. Prier, D. A. Rankic, D. W. C. MacMillan, Chem. Rev. 2013, 113, 5322-5363; b) I. Ghosh, L. Marzo, A. Das, R. Shaikh, B. König, ACC. Chem. Res. 2016, 49, 1566-1577; c) M. H. Shaw, J. Twilton, D. W. C. MacMillan, J. Org. Chem. 2016, $81,6898-6926$.

[8] S. Campagna, F. Puntoriero, F. Nastasi, G. Bergamini, V. Balzani, Top. Curr. Chem. 2007, 280, 117-214. 
[9] L. Flamigni, A. Barbieri, C. Sabatini, B. Ventura, F. Barigelletti, Top. Curr. Chem. 2007, 281, 143-203.

[10] I. Ghosh, T. Ghosh, J. I. Bardagi, B. König, Science 2014, $346,725-728$.

[11] a) L. Wang, W. Huang, R. Li, D. Gehrig, P. W. M. Blom, K. Landfester, K. A. I. Zhang, Angew. Chem. Int. Ed. 2016, 55, 9783-9787; b) Z. J. Wang, S. Ghasimi, K. Landfester, K. A. I. Zhang, Adv. Mater. 2016, 27, 6265-6270; C) R. Li, B. C. Ma, L. Wang, D. wang, H. Lu, K. Landfester, K. A. I. Zhang, ACS Catal. 2017, 7, 3097-3101.

[12] J. C. Theriot, C.-H. Lim, H. Yang, M. D. Ryan, C. B. Musgrave, G. M. Miyake, Science 2016, 352, 1082-1086.

[13] M. Majek, A. Jacobi Von Wangelin, Acc. Chem. Res. 2016, 49, $2316-2327$.

[14] D. M. Arias-Rotondo, J. K. McCusker, Chem. Soc. Rev. 2016, 45, $5803-5820$.

[15] I. Ghosh, B. König, Angew. Chem. Int. Ed. 2016, 55, 7676-7679.

[16] a) T. Miletić, A. Fermi, I. Orfanos, A. Avramopoulos, F. De Leo, N. Demitri, G. Bergamini, P. Ceroni, M. G. Papadopoulos, S. Couris, D. Bonifazi, Chem. Eur. J. 2017, 23, 2363-2378; b) T. Miletić, A. Fermi, I. Papadakis, I. Orfanos, N. Karampitsos, A. Avramopoulos, N. Demitri, F. De Leo, S. J. A. Pope, M. G. Papadopoulos, S. Couris, D. Bonifazi, Helv. Chim. Acta, 2017, DOI:10.1002/hlca.201700192.

[17] a) C. Song, T. M. Swager, Macromolecules 2009, 42, 1472-1475; b) H. Li, F. Zhang, S. Qiu, N. Lv, Z. Zhao, Q. Li, Z. Cui, Chem. Commun. 2013, 49, 10492-10494.

[18] a) Pummerer, E. Prell, A. Rieche, Berichte der Dtsch. Chem. Gesellschaft 1926, 59, 2159-2161; b) L. T. Rasmusson, L. J. P. Martyn, G. Chen, A. Lough, M. Oh, A. K. Yudin, Angew. Chem. Int. Ed. 2008, 47, 7009-7012; C) N. Lv, M. Xie, W. Gu, H. Ruan, S. Qiu, C. Zhou, Z. Cui, Org. Lett. 2013, 15, 2382-2385; d) T. Kamei, M. Uryu, T. Shimada, Org. Lett. 2017, 19, $2714-$ 2717 .

[19] D. Stassen, N. Demitri, D. Bonifazi, Angew. Chem. Int. Ed. 
2016, 55, 5947-5951.

[20] a) N. Kobayashi, M. Sasaki, T. Ohe, Semiconductor Device, Method of Manufacturing the Same, and Method of Forming Multilayer Semiconductor Thin Film, 2013, U.S. Patent 8399288 B2; b) P. Stoessel, A. Buesing, H. Hei, Novel Materials for Organic Electroluminescent Devices, 2010, U.S. Patent 2010/0013381 Al; C) M. Noda, N. Kobayashi, M. Katsuhara, A. Yumoto, S.-I. Ushikura, R.-I. Yasuda, N. Hirai, G. Yukawa, I. Yagi, K. Nomoto, T. Urabe, SID Symposium Digest of Technical Papers 2010, 41, 710-713.

[21] a) L. Wang, G. Duan, Y. Ji, H. Zhang, J. Phys. Chem. C 2012, 116, 22679-22686; b) R. Al-Aqar, A. C. Benniston, A. Harriman, T. Perks, ChemphotoChem 2017, 1, 198-205; C) N. Kobayashi, M. Sasaki, K. Nomoto, Chem. Mater. 2009, 21, 552-556.

[22] J. E. Bullock, M. T. Vagnini, C. Ramanan, D. T. Co, T. M. Wilson, J. W. Dicke, T. J. Marks, M. R. Wasielewski, J. Phys. Chem. B 2010, 114, 1794-1802.

[23] a) F. Würthner, Chem. Commun. 2004, 0, 1564-1579; b) F. Würthner, C. R. Saha-Möller, B. Fimmel, S. Ogi, P. Leowanawat, D. Schmidt, Chem. Rev. 2016, 116, 962-1052.

[24] a) N. Sakai, J. Mareda, E. Vauthey, S. Matile, Chem. Commun. 2010, 46, 4225-4237; b) S.-L. Suraru, F. Würthner, Angew. Chem. Int. Ed. 2014, 53, 7428-7448.

[25] A. K. Amegadzie, M. E. Carey, J. M. Domagala, L. Huang, R. G. Micetich, R. Singh, M. A. Stier, A. Vaisburg, J. P. Sanchez, WO1998019648A2, 1998.

[26] A. A. Berezin, A. Sciutto, N. Demitri, D. Bonifazi, Org. Lett. 2015, 17, 1870-1873.

[27] T. Ishiyama, M. Murata, N. Miyaura, J. Org. Chem. 1995, 60, $7508-7510$.

[28] D. Wu, Z. Chen, Y. Zhang, J. Zhang, S. H. Liu, J. Yin, J. Org. Chem. 2015, 80, 8443-8448.

[29] R. Martin, S. L. Buchwald, ACC. Chem. Res. 2008, 41, 14611473.

[30] Š. Vyskočil, L. Meca, I. Tišlerová, I. Císařová, M. Polášek, 
S. R. Harutyunyan, Y. N. Belokon, R. M. J. Stead, L. Farrugia,

S. C. Lockhart, W. L. Mitchell, P. Kočovský, Chem. Eur. J. $2002,8,4633-4648$.

[31] M. Murugavelu, P. K. M. Imran, K. R. Sankaran, S. Nagarajan, Mater. Sci. Semicond. Process. 2013, 16, 461-466.

[32] S. K. Lee, Y. Zu, A. Herrmann, Y. Geerts, K. Müllen, A. J. Bard, J. Am. Chem. Soc. 1999, 121, 3513-3520.

[33] J. D. Nguyen, E. M. D'Amato, J. M. R. Narayanam, C. R. J. Stephenson, Nat. Chem. 2012, 4, 854-859.

[34] J. J. Devery, J. D. Nguyen, C. Dai, C. R. J. Stephenson, ACS Catal. 2016, 6, 5962-5967.

[35] S. P. Pitre, C. D. McTiernan, J. C. Scaiano, ACC. Chem. Res. 2016, 49, 1320-1330.

[36] O. Amiri-Attou, T. Terme, M. Médebielle, P. Vanelle, Tetrahedron Lett. 2008, 49, 1016-1020.

[37] C. P. Andrieux, J.-M. Savéant, A. Tallec, R. Tardivel, C. Tardy, J. Am. Chem. Soc. 1997, 119, 2420-2429.

[38] D. D. M. Wayner, J. J. Dannenberg, D. Griller, Chem. Phys. Lett. 1986, 131, 189-191.

[39] A. Studer, D. P. Curran, Angew. Chem. Int. Ed. 2016, 55, 58102 .

[40] G. Magagnano, A. Gualandi, M. Marchini, L. Mengozzi, P. Ceroni, P. G. Cozzi, Chem. Commun. 2017, 53, 1591-1594.

[41] D. D. Tanner, J. J. Chen, L. Chen, C. Luelo, J. Am. Chem. Soc. 1991, 113, 8074-8081.

[42] C. P. Andrieux, J. M. Saveant, K. B. Su, J. Phys. Chem. 1986, $90,3815-3823$.

[43] A. Albini, Synthesis 1993, 3, 263-277.

[44] G. Nardi, I. Manet, S. Monti, M. A. Miranda, V. LhiaubetVallet, Free Radic. Biol. Med. 2014, 77, 64-70.

[45] A. Seret, E. Gandin, A. Van De Vorst, J. Photochem. 1987, 38, 145-155. 